\title{
Estratégias para ensinar e aprender em ambientes virtuais
}

\author{
Maria Elisabeth Bianconcinni de Almeida \\ Pontifícia Universidade Católica de São Paulo \\ bbalmeida@uol.com.br \\ Rosangela Del Vecchio \\ Pontifícia Universidade Católica de São Paulo \\ rosandv@gmail.com \\ Roseli Zen Cerny \\ Universidade Federal de Santa Catarina \\ rose@ced.ufsc.br \\ Susana Ester Krüger \\ Orquestra Sinfônica do Estado de São Paulo \\ Escola de Música e Belas Artes do Paraná \\ sekruger@uol.com.br
}

\section{Resumo}

Neste artigo apresenta-se uma análise das estratégias utilizadas em uma disciplina de pós-graduação, realizada na modalidade a distância, com uso de ambientes virtuais de aprendizagem. São apresentados e analisados os resultados de uma das estratégias utilizadas na disciplina: os seminários virtuais, realizados por convidados e pelos alunos como mediadores do processo. Conclui-se que no trabalho com ambientes virtuais, em distintos níveis e modalidades de ensino, tais ambientes devem ser integrados aos processos de ensino e de aprendizagem, tanto como recursos pedagógicos, quanto como objetos de estudo e reflexão com vistas a identificar suas contribuições a esses processos e a estimular nos professores e nos seus alunos o uso ativo, interativo, inteligente e crítico desta tecnologia.

Palavras-chave: educação a distância - ambientes virtuais - mediação

\begin{abstract}
This article analyzes some strategies used in an on-line post-graduation course conducted in virtual learning environments. One particular strategy is presented and analyzed: virtual seminars held by guest speakers and mediated by students. Results show that when working in virtual learning environments these have to be integrated with teaching-learning processes both as pedagogical resources and as objects of study and reflection to stimulate teachers and students to use this technology actively, interactively, intelligently and critically.
\end{abstract}

Key-words: distance education - virtual environments - mediation

\section{Introdução}

Este texto organiza-se na perspectiva de discutir as estratégias utilizadas em 
ambientes virtuais nos processos de formação à distância. Nossa opção é discutir as estratégias adotadas em uma disciplina realizada no primeiro semestre de 2006 no Programa de Pós-Graduação em Educação: Currículo, da Pontifícia Universidade Católica de São Paulo, na linha de pesquisa Tecnologias na Educação. Freqüentaram a disciplina 14 alunos (doutorandos e mestrandos) regularmente matriculados, e auxiliaram na sua organização duas monitoras e uma bolsista do curso de graduação em design. $\mathrm{O}$ ambiente virtual utilizado foi o Teleduc ${ }^{1}$. Contou-se também com quatro encontros presenciais no decorrer do semestre, sendo um no início das aulas para apresentação e discussão da proposta, e o último para avaliação conjunta da disciplina. Os outros encontros tiveram por finalidade refletir e analisar os avanços, dificuldades e estratégias adotadas para realinhar o planejamento e dar seqüência às atividades previstas.

Segundo o programa da disciplina, seu objetivo foi oferecer subsídios teóricos para o desenvolvimento dos alunos em relação às múltiplas dimensões que constituem o profissional (educador-pesquisador) sob o ponto de vista da educação a distância. A proposta da disciplina realizada a distância está assentada em princípios que visam à aprendizagem contextualizada, reflexiva e colaborativa com seus pares. Por se tratar de uma disciplina da pós-graduação, comprometida com a pesquisa e a produção do conhecimento, apresenta também um caráter investigativo em consonância com os avanços das tecnologias da comunicação e da informação, que impõem à sociedade e ao mundo educacional uma dinâmica de atuação inovadora. Dentre todas as estratégias, optou-se neste artigo pela análise de uma delas: os seminários virtuais.

\section{Ambientes virtuais e educação}

O uso de ambientes virtuais de aprendizagem (AVA) na educação tem sido foco de discussões e pesquisas em diferentes áreas de conhecimento. É certo que as pesquisas que tratam da tecnologia em si aparecem em maior quantidade, em detrimento daquelas que fazem uma discussão pedagógica sobre o uso destes ambientes. É importante identificar duas abordagens de estratégias nos processos de ensino e de aprendizagem, a saber: uma intrinsecamente relacionada ao planejamento do professor e à proposta do curso, fundamentada nos princípios teóricos que norteiam os objetivos esboçados, e as traçadas pelo próprio aluno, as estratégias de estudo, que o auxiliam na organização e controle da auto-aprendizagem. Em EaD, estes processos são inter-relacionados, embora se dêem muitas vezes em momentos distintos. Essa prática discente tem maior relevância quando a educação se dá à distância, devido às peculiaridades inerentes a essa modalidade, incidindo diretamente no planejamento do professor.

Nesse sentido, no planejamento de um curso de formação na modalidade à distância, a principal razão para a escolha deste ou daquele meio, assim como a combinação dos diversos meios de comunicação, deve sempre levar em consideração a aprendizagem dos estudantes. É importante perguntar:

- Quais são as características do grupo de alunos?

- Quais os resultados esperados no uso dos meios pelos alunos?

- Esses meios permitem a realização de trabalhos práticos?

- Os alunos poderão usufruir efetivamente desses meios?

- Há coerência com a lógica de organização do curso à distância pretendido?

- Esses meios permitem uma ação pedagógica interdisciplinar?

\footnotetext{
${ }^{1} \mathrm{O}$ TelEduc é uma plataforma de ensino e aprendizagem via internet desenvolvida pelo NIED/Unicamp. www.nied.unicamp.br/teleduc
} 
Então, por onde começar quando estamos planejando um curso utilizando ambientes virtuais de aprendizagem?

\section{Planejamento e estratégias}

O planejamento das estratégias de ensino e de aprendizagem na educação online deve ser construído tal qual no caso de uma disciplina presencial e, da mesma forma, muitas vezes é reconstruído no desenrolar do curso, conforme o movimento adotado pelo grupo, bem como pela articulação entre a intencionalidade pedagógica do curso com as próprias características e possibilidades que os ambientes virtuais oferecem. No entanto, as alterações de planejamento na educação on-line devem ser minimizadas e sempre comunicadas com clareza e antecedência. Neste sentido, para auxiliar no desenvolvimento do trabalho on-line, CERQUEIRA (2005, p.39-40) sugere que o papel do professor seja definido a partir do contexto emergente, como

um professor a posteriori e não a priori, ou seja, seu papel será definido de trás para frente, dadas as necessidades que vão sendo "coladas" no processo de ensino e aprendizagem a distância, e que podem, por sua vez, ser apenas "rascunhadas", nunca "passadas a limpo" a priori. Ele deverá sempre estar aberto para o novo, para o porvir.

Pelas especificidades que o meio oferece, também se torna fundamental a ambientação dos alunos com o AVA, para se sentirem seguros e à vontade na sala de aula virtual.

ALMEIDA (2003, p.10) considera que no planejamento também devem ser considerados fatores essenciais como a organização, a disponibilidade e a interação constantes para o alcance dos objetivos pedagógicos da $\mathrm{EaD}$ :

ensinar em ambientes digitais e interativos de aprendizagem significa: organizar situações de aprendizagem, planejar e propor atividades; disponibilizar materiais de apoio com o uso de múltiplas mídias e linguagens; ter um professor que atua como mediador e orientador do aluno, procurando identificar suas representações de pensamento; fornecer informações relevantes, incentivar a busca de distintas fontes de informações e a realização de experimentações; provocar a reflexão sobre processos e produtos; favorecer a formalização de conceitos; propiciar a interaprendizagem e a aprendizagem significativa do aluno.

ALMEIDA e PRADO (2006, p.2) chamam-nos a atenção para que o trabalho com as tecnologias não seja uma mera transposição das estratégias do presencial, empobrecendo o processo por desconsiderar as características intrínsecas ao meio de suporte ao curso, as quais interferem no conteúdo das informações e nas formas de comunicação.

Fazer educação à distância como a virtualização da prática de sala de aula acaba empobrecendo o processo de ensino e aprendizagem. Primeiro porque esta virtualização embora seja baseada na reprodução do contexto presencial, induz a perder elementos específicos fundamentais da presencialidade e, segundo, porque ela não incorpora as características dos recursos do ambiente virtual e, portanto, deixa de se beneficiar de contribuições que esses ambientes podem trazer ao ensino e à aprendizagem tais como a interação 
multidirecional, os registros digitais e a recuperação instantânea das intervenções e a organização das informações com os mecanismos automáticos de busca.

Outra recomendação de NEVADO (2005) é que as organizações dos ambientes virtuais de aprendizagem tenham como conseqüência o abandono da perspectiva de "ensino na rede" em favor de processos de "aprendizagem em rede", priorizando: a) a formação de redes de interações; b) a criação de novos "espaços" de aprendizagem webfólios, páginas web, blogs; c) 0 estabelecimento de novas temporalidades; d) flexibilizações nas relações entre professores e alunos e entre os grupos de alunos; e) estímulo à troca de diferentes pontos de vista; f) diversidade de informações que podem ser reinterpretadas e reelaboradas; g) ao professor cabe a função de propiciar a aprendizagem, o diálogo, provocar situações de dúvidas (desequilíbrios) e apoiar as reconstruções (novos conhecimentos); h) ao aluno cabe uma postura ativa: experimentar, compartilhar, criar, interagir.

A opção pelos recursos oferecidos no ambiente virtual deve levar em consideração o perfil dos alunos, a proposta pedagógica do curso e as condições de acesso às tecnologias em uso. Assim, nestes processos de "aprendizagem em rede", uma das estratégias mais utilizadas é a formação de grupos de alunos, aos quais é oferecida crescente autonomia na realização de tarefas.

\section{O processo de aprendizagem on-line}

QUEVEDO (2005), na conclusão de sua tese, lembra que, no início, o aluno precisa ser cuidadosamente orientado para saber navegar no ambiente, isto é: como ligar o computador, abrir um navegador, digitar o endereço do curso, conectar-se, clicar em links, abrir arquivos de áudio e de vídeo, digitar texto etc. São ações em um primeiro momento, até chegar ao ponto de automatizar a ação e ela se tornar operação segundo a concepção da teoria da atividade, base dos estudos de Quevedo. Na pesquisa desta autora, os alunos precisaram de cerca de duas semanas para incorporarem as operações necessárias para usar tais ferramentas em sua rotina de trabalho.

Estes resultados são semelhantes aos obtidos na pesquisa-ação de SALMON (2000), realizada na Open University sobre as interações entre formadores ( $e$ moderators) e alunos em $\mathrm{EaD}$, principalmente nas "CMC" - Computer-mediated Conferencing - em cursos de MBA. Como resultado, a autora desenvolveu uma proposta de interações on-line, cujos cinco estágios descrevem a evolução das interações e as habilidades técnicas e de formação pedagógica (ou mediação) do formador.

Cada um dos estágios deve ser cuidadosamente planejado:

a) Acesso e motivação: o formador precisa motivar e encorajar os alunos para que permaneçam na atividade, por meio de explicações sobre a importância da colaboração, os objetivos pedagógicos do ambiente virtual, sua estrutura e, inclusive, formas de envio de trabalhos para avaliação.

b) Socialização on-line: o formador deverá organizar estratégias que favoreçam a integração dos participantes, fornecer apoio técnico e pedagógico, explicitar os objetivos, direcionar as atividades. Ele deverá estar atento para "resolver problemas, conciliar indivíduos aparentemente alienados, ajudar os participantes que têm interesses e necessidades similares a se encontrarem" (SALMON, 2000, p.30).

c) Troca de informações: os participantes trocam informações de forma mais rápida e eficaz, e a interação ocorre entre os alunos e o conteúdo e entre os participantes, principalmente entre o formador e os alunos (SALMON, 2000, p.29).

d) Construção do conhecimento: há um aumento da interatividade e da 
comunicação entre os alunos - que se comportam mais como autores do que como transmissores de informação. É importante lançar desafios e problematizações que estimulem idéias e reflexões (SALMON, 2000, p.32-33).

e) Desenvolvimento: neste estágio, os participantes se tornam "responsáveis pelo seu aprendizado através das oportunidades proporcionadas" e precisam de pouco suporte além do que está normalmente acessível. Participantes mais experientes podem assumir o papel de formadores, para auxiliar os mais novos no grupo (SALMON, 2000, p.35).

Como veremos adiante, na disciplina em análise as estratégias partiram de atividades individuais e mais direcionadas e evoluíram para atividades em duplas ou trios (grupos). Desta forma, gradativamente, foi oferecida maior autonomia e responsabilidade para os alunos (experientes ou não em EaD), e todos puderam vivenciar o papel de formadores. Podemos considerar que os processos de ensino e de aprendizagem on-line desta disciplina remetem-nos aos estágios descritos acima. Estes podem contribuir para aumentar nossa compreensão sobre as estratégias que possivelmente seriam mais adequadas para cada estágio, atendendo assim as diferentes necessidades, interesses e possibilidades dos alunos.

\section{Um olhar sobre uma de muitas estratégias}

$\mathrm{Na}$ disciplina em análise, a docente optou pelo ambiente virtual TelEduc como plataforma de trabalho. Num levantamento feito com recursos do próprio sistema, coletou-se o número de acessos às ferramentas, conforme apresentado na Tabela 1 . Observamos que o Fórum de Discussão foi o espaço mais utilizado pelo grupo, com um total de 1.723 acessos, incluindo-se os acessos da formadora, dos alunos participantes e de duas professoras convidadas.

Consideramos que a preferência pela ferramenta Fórum, resultando em $35 \%$ do total em relação às outras, deve-se à proposta pedagógica e à metodologia adotada. Entretanto, as características dessa interface, dentre as quais destacamos o acesso assíncrono, é outro fator determinante de seu uso.

\begin{tabular}{|c|c|c|c|c|c|c|}
\hline \multirow{2}{*}{$\begin{array}{c}\text { Participantes } \\
\text { (alunos, convidadas* } \\
\text { e professora**) }\end{array}$} & \multicolumn{5}{|c|}{ Ferramentas } & \multirow{2}{*}{$\begin{array}{c}\text { Média de } \\
\text { participa- } \\
\text { ção/acessos }\end{array}$} \\
\hline & Fóruns & Correio & $\begin{array}{l}\text { Bate- } \\
\text { papo }\end{array}$ & Portfólio & $\begin{array}{c}\text { Diário de } \\
\text { bordo }\end{array}$ & \\
\hline ACMC* & 32 & 26 & 5 & 8 & 2 & 14,6 \\
\hline CG & 67 & 94 & 68 & 15 & 17 & 52,2 \\
\hline FLP & 113 & 88 & 33 & 18 & 2 & 50,8 \\
\hline LCBR & 139 & 161 & 112 & 12 & 25 & 89,8 \\
\hline MBMR & 135 & 122 & 74 & 9 & 17 & 71,4 \\
\hline MCD & 189 & 142 & 98 & 94 & 27 & 110 \\
\hline MEBA** & 110 & 152 & 68 & 21 & 14 & 73 \\
\hline MAFB & 112 & 67 & 55 & 26 & 7 & 53,4 \\
\hline RAAD & 130 & 158 & 86 & 22 & 11 & 81,4 \\
\hline RDV & 165 & 176 & 120 & 25 & 17 & 100,6 \\
\hline $\mathrm{RC}$ & 196 & 169 & 149 & 50 & 40 & 120,8 \\
\hline SS & 122 & 41 & 79 & 17 & 21 & 56 \\
\hline SEK & 85 & 101 & 58 & 20 & 12 & 55,2 \\
\hline VGS & 60 & 38 & 28 & 7 & 5 & 27,6 \\
\hline VMMC* & 46 & 28 & 18 & 7 & 5 & 20,8 \\
\hline VAF & 7 & 1 & 1 & - & - & 1,8 \\
\hline WSR & 15 & 11 & 6 & 17 & 4 & 10,6 \\
\hline \multirow{2}{*}{ Total } & 1723 & 1575 & 1058 & 368 & 226 & \multirow[t]{2}{*}{49,50} \\
\hline & $35 \%$ & $32 \%$ & $21 \%$ & $7,5 \%$ & $4,5 \%$ & \\
\hline
\end{tabular}

Tabela 1: Relatório de Frequiência das ferramentas do ambiente 
Entre as diversas atividades propostas durante a disciplina, fizeram parte da programação sete seminários virtuais, apresentados na Tabela 2. Os seminários se distinguiram em duas categorias: com a mediação de convidados e com a mediação dos alunos. Os alunos organizaram-se em cinco grupos por temática de interesse e, durante uma semana, assumiam o papel de formadores, planejando e executando as atividades. Os seminários mediados pelas convidadas estenderam-se por no mínimo três semanas.

\begin{tabular}{|l|l|c|}
\hline \multicolumn{1}{|c|}{ Temáticas dos Seminários } & \multicolumn{1}{c|}{ Período } & $\begin{array}{c}\text { No. } \\
\text { acessos }\end{array}$ \\
\hline $\begin{array}{l}\text { Seminário 1 - O professor e os conhecimentos necessários para atuar em } \\
\text { ambientes virtuais }\end{array}$ & $22-29 / 05 / 2006$ & 24 \\
\hline Seminário 2 - Estratégias para ensinar e aprender em ambientes virtuais & $29 / 05-05 / 06 / 2006$ & 46 \\
\hline $\begin{array}{l}\text { Seminário 3 - Formação de professores de Educação Profissional e suas } \\
\text { correlações com ambientes virtuais }\end{array}$ & $05-12 / 06 / 2006$ & 65 \\
\hline Seminário 4 - Mediação pedagógica e EAD & $12-20 / 06 / 2006$ & 36 \\
\hline Seminário 5 - Formação do professor mediador/tutor & $20-28 / 06 / 2006$ & 24 \\
\hline $\begin{array}{l}\text { Seminário com convidada 1 - Mediação pedagógica em ambientes } \\
\text { digitais de ensino e aprendizagem a distância }\end{array}$ & $08 / 04-01 / 05 / 2006$ & 59 \\
\hline Seminário com convidada 2 - Avaliação formativa na educação on-line & $24 / 04-13 / 05 / 2006$ & 41 \\
\hline \multicolumn{2}{|c|}{ Total } & $\mathbf{2 9 5}$ \\
\hline
\end{tabular}

Tabela 2: Seminários Virtuais

\section{A - Seminários com mediação de professoras convidadas}

As professoras convidadas são egressas do mesmo Programa de Pós-graduação e desenvolveram suas pesquisas na linha Novas Tecnologias na Educação. O primeiro seminário foi intitulado "Mediação pedagógica em ambientes digitais de ensino e aprendizagem à distância", e o segundo foi "Avaliação formativa na educação on-line". Foi solicitada a leitura das dissertações das autoras (CERQUEIRA, 2005; CALDEIRA, 2006), e a discussão foi realizada por meio do Fórum e Bate-papo. O número de participações nas discussões realizadas no Fórum pode ser considerado excelente, tendo em vista o total de participantes e o período de duração (10 dias) desses seminários: 59 acessos no primeiro, e 41 acessos no segundo seminário.

Dentre os fatores que podem ter contribuído e estimulado o envolvimento dos alunos nesta atividade, destacamos a qualidade da ação mediadora, determinada pela habilidade de observação ou leitura das entrelinhas, no sentido de perceber as necessidades do grupo, interferindo com precisão e sensibilidade, estimulando e interpelando os alunos para a reflexão, num movimento de troca colaborativa que aquecia gradativamente as discussões. O domínio do tema também interfere no processo comunicativo, não somente no fluxo, como na qualidade das comunicações - princípio básico de qualquer processo educativo.

\section{B - Seminários com mediação dos alunos}

$\mathrm{Na}$ segunda semana da disciplina, a professora já indicava na agenda os primeiros passos para a produção dos seminários com a mediação dos alunos, que se organizariam em duplas ou trios com o intuito de investigar e propor o desenvolvimento de atividades virtuais sobre temas convergentes e através do fórum "Parceiro temático".

O primeiro seminário foi iniciado na décima semana da disciplina. Nas quatro semanas seguintes, sempre às segundas-feiras, um novo grupo de alunos assumia o 
status de formador durante sete dias, responsabilizando-se pelo planejamento e execução das atividades.

Os grupos foram criativos e dinâmicos, utilizando uma ou mais estratégias, entre as quais destacamos: interpretação de imagem, envio de correspondência por correio formal/convencional, estudo de caso, pequeno causo, produção de apresentações, formação de duplas, vídeos e textos de apoio. Todas as estratégias propostas visavam a motivar a participação e garantir a interação entre os colegas. Alguns grupos também sugeriram a utilização das diferentes ferramentas disponíveis no ambiente. A interface do Fórum, por suas características já citadas anteriormente, foi o centro das interlocuções, em que argumentos e questionamentos constituíram um entrelaçamento de idéias e reflexões das diferentes vozes, num processo importante de desconstrução e reconstrução do pensamento. Outra ferramenta bastante utilizada foi o Bate-papo, para discussão síncrona durante e/ou para o fechamento dos seminários. A docente responsável pela disciplina participou de todos os seminários numa posição comediadora, intervindo de maneira precisa e, sem interferir na autonomia dos grupos, alinhavava o foco da discussão ou estimulava os questionamentos.

Utilizar o seminário virtual em grupo como uma estratégia de aprendizagem, além de provocar a reflexão e a aprendizagem de um determinado tema, também contribui para o exercício de respeito ao ritmo e às idéias do outro, o que requer uma postura de flexibilidade, respeito e sintonia, num vai-e-vem entre o individual e o coletivo, tanto no planejamento como na mediação do fórum. Desenvolver esse trabalho proporciona aos alunos a compreensão sobre o significado do planejamento para a realização de atividades em ambiente virtual.

\section{C - O percurso de um seminário}

Aqui analisamos a organização e as estratégias adotadas no seminário dois, intitulado Estratégias para ensinar e aprender em AVA. O grupo responsável era formado por três alunas que tinham em comum o mesmo interesse pelo tema. Trabalhamos na maior parte do tempo à distância, utilizando as ferramentas do ambiente (portfólio de grupo, e-mail e bate-papo) para troca de informações, planejamento do seminário e elaboração de material, o que favoreceu a interlocução e execução da atividade.

O grupo optou pelo Estudo de Caso, como estratégia, envolvendo a criação de um cenário, visando a promover discussão no fórum sobre o tema escolhido e a criar interação entre os participantes. Ao todo foram postados 46 comentários, com a participação de todos os alunos.

Como subsídio ao desenvolvimento do seminário foram disponibilizados um artigo, uma entrevista da docente responsável pela disciplina sobre estratégias e um pequeno texto elaborado pelas alunas do grupo. A pesquisa bibliográfica revelou escassez de material sobre o assunto.

A primeira estratégia utilizada foi enviar pelo correio convencional um convite, ilustrado por uma charge, com o objetivo de surpreender positivamente os alunos. Posteriormente, o mesmo conteúdo foi enviado também pelo $e$-mail do ambiente, com o seguinte questionamento: "Na ação pedagógica a estratégia escolhida pode parecer ao professor a mais adequada. Será que atende a necessidade do aluno?".

Consideramos que nossa proposta era desafiadora por discutirmos sobre as estratégias mais adequadas para tal situação e, concomitantemente, aplicá-las com vistas a motivar a participação dos alunos, a provocar trocas e reflexões que contribuíssem com o estabelecimento de novas articulações e produção de conhecimento sobre o tema 
geral da disciplina. Outro aspecto importante, e já citado nesse artigo, foi a experiência do trabalho em grupo à distância, parceria que se revelou agradável e produtiva, pautada na cooperação e cumplicidade decorrente do vínculo entre o compromisso e a confiança nas parceiras de equipe.

Para manter as discussões aquecidas, organizamos uma tabela de acesso ao Fórum de maneira que, diariamente, pelo menos uma integrante do grupo responderia aos comentários com questionamentos que incentivassem a elaboração de outras perguntas, conduzisse a reflexões e novas elaborações. Contávamos com a vantagem de o grupo de alunos estar completamente integrado ao ambiente e entre si.

Nossa experiência revelou que, para manter o ritmo das discussões e a participação dos estudantes, é necessária a intervenção constante do formador, experenciando alternativas. Acreditamos que os AVA devem ser integrados ao ensino e à aprendizagem, tanto como recursos pedagógicos, quanto como objetos de estudo e reflexão, de modo a estimular nos professores e nos seus alunos o uso ativo, interativo, inteligente e crítico desta tecnologia.

\section{Considerações finais}

Se acreditamos numa educação que privilegia o diálogo, a escolha das estratégias para as ações de formação com uso de ambientes virtuais exige uma postura crítica e criativa dos educadores. É necessário ressignificar as nossas práticas, investindo naquelas que privilegiem a troca, o envolvimento dos participantes, a investigação, a negociação de sentidos e a (re)produção de conhecimento. Na experiência analisada neste artigo, destacamos como significativas a escolha das ferramentas do ambiente, a postura adotada pelos mediadores, o respeito ao tempo de cada participante, a criatividade, a diversidade de estratégias adotadas no planejamento dos seminários e as novas aprendizagens. Todas as estratégias propostas visavam a motivar a participação e garantir a interação entre os colegas com o objetivo de construir conhecimento sobre as temáticas em estudo.

Como sabemos, essa estratégia didático-pedagógica, o seminário, é utilizada há muito tempo no ensino presencial com objetivo de discutir e aprofundar um tema previamente estipulado. Na educação on-line é adotada com o mesmo intuito; no entanto, a dinâmica se concentra muito mais na interlocução entre o mediador e os participantes e na negociação de sentidos do que na exposição e transmissão do conteúdo. Este é disponibilizado no ambiente como subsídio e apoio para os debates e, após a conclusão do seminário, cada grupo faz sua avaliação junto com a formadora responsável pela disciplina e produz um artigo sobre a análise da experiência com as respectivas elaborações conceituais.

Nessa disciplina, um diferencial se deu nos seminários mediados pelos alunos que, além de disponibilizarem textos, também empregaram um conjunto de outras estratégias com a intencionalidade de estimular a participação dos colegas, visando a ampliar o repertório de conhecimento e o aprendizado colaborativo. Esta atividade consistiu num triplo desafio aos alunos que assumiram o papel de formadores. $\mathrm{O}$ primeiro foi o de planejar e organizar as atividades utilizando o ambiente on-line, permitindo o uso de ferramentas até então pouco utilizadas no papel de formador. $\mathrm{O}$ segundo desafio foi o de mediar o seminário no ambiente virtual, pois trazer os colegas para a discussão não foi um movimento fácil. O terceiro desafio foi a produção de um artigo que retratasse a análise do processo vivenciado na disciplina. Contribuíram para a participação a motivação inicial e o espaço privilegiado para que cada um dos alunos pudesse trazer as suas experiências pessoais e profissionais sobre a temática em discussão, assim como a atribuição do papel de formadores nos seminários. 
É certo que temos um longo caminho a percorrer nesta área, e que o sucesso de determinadas estratégias adotadas por um grupo de alunos ou formador não é garantia de sucesso para outros grupos. No entanto, evidencia-se que precisamos investir na colaboração e envolvimento dos participantes como co-mediadores do processo.

\section{Referências bibliográficas}

ALMEIDA, Maria Elizabeth Bianconcini. Educação a Distância na Internet: Abordagens e Contribuições dos Ambientes digitais de Aprendizagem. In: Educação e Pesquisa. Revista da Faculdade de Educação da USP. São Paulo: v.29, n.2, jul./dez.2003

ALMEIDA, Maria Elizabeth Bianconcini e PRADO, Maria Elisabette. B. Estratégias em Educação a Distância: a plasticidade na prática pedagógica do professor online. mimeo (circulação restrita), 2006.

BARRETO, Raquel Goulart. A apropriação educacional das tecnologias de informação e da comunicação. In: LOPES, A \& MACEDO, E. (org.) Currículo: debates contemporâneos. São Paulo: Cortez, 2002.

BELLONI, Maria Luiza Educação a distância. Campinas, SP: Autores Associados. 1999.

- Ensaio sobre a educação a distância no Brasil. Educ. Soc. [online]. abr. 2002, vol.23, no.78, p.117-142. Disponível em: www.scielo.br/scielo.php?script=sci_arttext\&pid=S010173302002000200008\&1 ng=pt\&nrm=iso . ISSN 0101-7330. Capturado em 05/2005.

CALDEIRA, Ana Cristina Muscas. Avaliação Formativa na Educação On-line. São Paulo: PUC/PPGC, 2006. Dissertação de Mestrado.

CERQUEIRA, Valdenice Minatel Melo de. Mediação Pedagógica e chats educacionais: a tessitura entre colaborar, intermediar e co-mediar. São Paulo: PUC/PPGC, 2005. Dissertação de Mestrado.

MASETTO, Marcos T. Competência pedagógica do professor universitário. São Paulo: Summus, 2003.

NEDER, Maria Lúcia. A formação do professor à distância: desafios e inovações na direção de uma prática transformadora. Florianópolis, 2004. Tese de Doutorado.

NEVADO, Rosane Aragon Nevado. Ambientes virtuais que potencializam as relações de ensino-aprendizagem. In: Boletim Salto para o Futuro. 2005. Disponível em: www.tvebrasil.com.br/salto. Capturado em: 05/2006

QUARTIERO, Elisa Maria et alii. Introdução à Educação à Distância. Florianópolis: UFSC/EAD/CED/CFM, 2005.

QUEVEDO, Angelita Gouveia. Atividade, contradições e ciclo expansivo de aprendizagem no engajamento de alunos em um curso online. São Paulo: PUC/LAEL, 2005. Tese de Doutorado.

SALMON, Gilly. E-Moderating: the key to teaching and learning online. 2nd ed. London: Kogan Page, 2000. 
